https://helda.helsinki.fi

\title{
Methodeutic and the order of inquiry
}

\section{Bergman, Mats}

2018-01

Bergman, M 2018 , ' Methodeutic and the order of inquiry ' , Semiotica , no. 220 , pp. 269-299 . https://doi.org/10.1515/sem-2016-0225

http://hdl.handle.net/10138/298247

https://doi.org/10.1515/sem-2016-0225

publishedVersion

Downloaded from Helda, University of Helsinki institutional repository.

This is an electronic reprint of the original article.

This reprint may differ from the original in pagination and typographic detail.

Please cite the original version. 


\section{Mats Bergman* \\ Methodeutic and the order of inquiry}

https://doi.org/10.1515/sem-2016-0225

Abstract: Although C. S. Peirce frequently notes the importance of the branch of logic he designates "rhetoric" or "methodeutic," he only rarely specifies what this subdivision is meant to involve. This article reassesses the role of methodeutic in Peirce's classification of the sciences, as well as the methodical significance of this classificatory endeavor itself. The article argues that the classification of sciences is best comprehended as a distinctive phase of methodeutic investigation, which examines actual manifestations of inquiry as well as abstract principles in crafting a normatively guiding conception of the scientific venture. It is further argued that the strict hierarchy on which Peirce bases his classification needs to be tempered to allow for a more flexible ordering, in which so-called "dynamical relationships" between inquiries are considered alongside the top-down perspective of "rational precedence."

Keywords: methodeutic, C. S. Peirce, classification of sciences, speculative rhetoric, inquiry

In an 1898 entry in his Logic Notebook, C. S. Peirce sketches a provisional division of labor for his logical trivium of grammar, critic, and rhetoric. ${ }^{1}$ Intriguingly, the third branch is allotted the rather irregular trio of objective logic, application of logic to mathematics (etc.), and methodology (MS 339: 145r). While this fragment no doubt raises more questions than it answers, it does mark a kind of breaking point in the development of Peircean rhetoric. For it is probably the first time that Peirce explicitly places the general investigation of methods within the purview of this logical study - and, anticipating things to come, simultaneously also expresses a distinct

1 Peirce introduces his trivium - originally composed of grammar, logic, and rhetoric - in the 1860s as a division of "symbolistic." The trichotomy more or less disappears from his writings in the 1870 s and 1880 s, only to return in the 1890 s along with a rekindled interest in semiotic and growing focus on the classification of the sciences.

*Corresponding author: Mats Bergman, University of Helsinki, 00100 Helsinki, Finland, E-mail: mats.bergman@helsinki.fi 
dissatisfaction with "speculative rhetoric" as a label for the culminating branch. $^{2}$

Peirce's terminology is obviously in some flux in the Minute Logic of 19011902, where he employs the alternative names "transuasional ${ }^{3}$ logic" and "methodeutic" beside "speculative rhetoric." In this complex manuscript, Peirce submits that rhetoric "is substantially what goes by the name of methodology, or better, of methodeutic," but he continues to define it broadly as "the doctrine of the general conditions of the reference of Symbols and other Signs to the Interpretants which they aim to determine" (CP 2.93 [1902]). Compare this later characterization to Peirce's 1867 definition of formal rhetoric as a "conceivable science" that "would treat of the formal conditions of the force of symbols, or their power of appealing to a mind, that is, of their reference in general to interpretants" (W 2: 57 [1867]). Arguably, two significant differences are noticeable - the expansion of rhetoric (and semiotic in general) beyond the symbolic and the subtle emphasis on determining interpretants as a goal - but overall, I would say that the general rhetorical focus has not shifted all that dramatically in 35 years. It is still at heart a general study of the relationships between signs and their interpretants.

The changes become more noticeable in Peirce's 1902 application to the Carnegie Institution, where "rhetoric" is definitely replaced by "methodeutic." Although "speculative rhetoric" makes a couple of notable comebacks a few years down the road, Peirce clearly favors the new designation, with its more narrowly scientific overtones, in his later writings. This is not to say that broader considerations of inquiry would not feature prominently in some of Peirce's earlier characterizations of speculative rhetoric; in the 1890s, he for example defines the third branch as an investigation of "the laws of the development of scientific representations" (MS 787: 11 [c. 1895-18964]) and as a "study of those general conditions under which a problem presents itself for solution and those

2 Peirce's exact phrase is: "only the term is bad."

3 Transuasion is basically the third category of mediation; the technical term is meant to suggest "translation, transaction, transfusion, transcendental, etc." (CP 2.89 [1902]).

4 This quote stems from a manuscript ("That Categorical and Hypothetical propositions are one in essence") that has been scattered around the nachlass and the Collected Papers. The dating is uncertain. However, in one fragment (MS 805), Peirce refers to a paper on his table, where the phrase "some questions were asked the junior class in psychology in Columbia College in March 1893" occurs. This is most likely a reference to J. McKeen Cattell's article "Measurements of the Accuracy of Recollection” (Science, Dec 6, 1895), where, but for the omission of the word "were," this exact sentence can be found. This, in addition to the fact that the manuscript in question deals with similar topics as Peirce's "The Regenerated Logic" from 1896, strongly suggests that it was most likely written in late 1895 or early 1896. 
under which one question leads on to another" (CP 3.430 [1896]). But even so, the explicit turn to methodeutic in the early 1900s is not a minor nominal adjustment. It is an indication of a substantial modification of emphasis that manifests itself in a growing - and sometimes exclusive - focus on methods of inquiry. Indeed, it is just to avoid confusion with the more concrete meaning of "method" that Peirce prefers the neologism "methodeutic" as a new name for this specialization of semiotic logic (he dismisses "methodology" as too “German” for his tastes; MS 452: 6-7 [1903]; cf. CP 2.207 [1902]). Consequently, methodeutic is characterized as the study of "the general principles upon which scientific studies should be carried on" (MS 1334: 28 [1905]). As such, its central concern is the problem of "how to conduct an inquiry" (NEM 3: 207 [1911]). But more fully, the third branch is supposed to explore "the methods that ought to be pursued in the investigation, in the exposition, and in the application of truth" (EP 2: 260 [1903]). And a key component of the second of these three methodeutic tasks is the examination and elucidation of how inquiries are to be ordered and arranged (MS 452: 6 [1903]; MS 606: 17 [c. 1905-1906]).

This systemic-expository function of methodeutic has not received much attention in the literature. I suspect that one reason for the neglect is that Peirce normally assigns the task of organizing the scientific disciplines to the "science of review" or "systematic science" (EP 2: 259 [1903]; MS 601: 26 [c. 1906]: EP 2: 458 [c. 1911]), and not to the set of "heuretic sciences" (i.e., sciences of discovery) to which methodeutic belongs. Science of review is meant to proceed from digests of discoveries toward the formation of an inclusive "philosophy of science" (EP 2: 258-2.259 [1903]). The

\footnotetext{
systematic scientists sort out the results of the heuretic scientists, subject these results to a criticism more comprehensive than the latter scientists in their narrow specification are in a condition to apply, deduce the best conclusions, which they digest in handbooks, and go on first to the classification of the sciences and to the characterization of the different classes, and finally proceed to such broad surveys as the "Philosophie Positive" of Comte and the "Synthetic Philosophy" of Spencer. (MS 601: 26 [c. 1906])
}

Somewhat inconclusively, Peirce suggests that science of review is pursued either to facilitate practical applications of theoretical findings (MS 1338: 3 [c. 1905-1906]) or for autonomous ends of its own (MS 673: 47 [c. 1911); but he consistently portrays it as a retrospective endeavor that does not contribute to the active quest for new knowledge. Thus, while science of review needs to fill gaps left by piecemeal heuretic inquiries - and in this respect, its practitioners can be said to conduct independent investigations for their own generalist purposes (NEM 4: 191 [1904]) - it is nonetheless entirely dependent on prior pursuits of discovery for its materials. 
Accordingly, it seems that the classification of the sciences - on which Peirce expends a rather substantial amount of labor - should primarily be understood as a retroactive undertaking, a first systematic step toward organizing digested knowledge. As such, it would not be a concern of methodeutic or any other science of discovery. Although it seems reasonable enough to surmise that the role of the third branch of logic would be to lay out the general principles that are to be used in the systematic cataloguing of the sciences, it must also be conceded that Peirce does not consistently gather the tenets purportedly underpinning his arrangements under the rubric of "methodeutic" - or within any other specific line of inquiry, for that matter. At times, he seems content to leave the sorting of the sciences entirely to the retrospective phase; but in other instances, he suggests that the classificatory principles are to be understood as "prelogical notions" that in some sense inform all modes of inquiry - or at least logic and the "postlogical sciences."

In this article, I will reassess the role of the third branch of logic in Peirce's arrangement of the sciences, as well as the methodical significance of this classificatory endeavor itself. This turns out to be a more complex - and possibly also much more significant - issue than one might initially expect. As we find that methodeutic is meant to study all aspects of scientific method - of discovery, of review, and of application - it inevitably involves a kind of bird's eye view of the scientific endeavor as a whole, a perspective that separates it from any other specialization in the Peircean system. But at the same time, the hierarchical principles of classification appear to pose restrictions on the disciplinary uses of the inquiry into methods. For methodeutic is not simply portrayed as a broad study of techniques and procedures of scientific research; it also occupies a definite position in Peirce's hierarchy of sciences, which prescribes its doctrinal dependencies and the legitimate field of application of its results.

This points toward a potential duality in Peirce's classificatory project. On the one hand, his organization of the sciences is depicted as a secondary pursuit that should merely summarize and systematize the results of the primary inquiries that discover new facts. Yet, on the other, its principles of arrangement disclose key "architectonic" dependencies between the heuretic disciplines and even dictate the sequence in which such investigations ought to be practiced, especially in philosophy. Strikingly often, his classificatory efforts rise above the mere organized cataloguing of extant inquiries, and in effect become an arena in which he works out some of the fundamental tenets of his system. Here, I will put forward the hypothesis that this is best comprehended as a distinctive phase of methodeutic investigation that looks to actual manifestations of inquiry as well as abstract principles in crafting a normatively guiding, yet eminently fallible, conception of the scientific venture. 
This is certainly not an uncontroversial proposition, because my reconstruction entails that the strict "Comtean" hierarchy on which Peirce bases his classification needs to be tempered to allow for a more flexible ordering, in which what he designates "dynamical relationships" between inquiries are considered alongside the top-down perspective of "rational precedence." I will proceed toward this conclusion via an appraisal of the broad precepts on which Peirce bases his arrangement of scientific inquiries, taking stock of certain strains between its descriptive and normative facets as well as the thorny question of "prelogical notions." I will further argue that an important part of the prospective task of methodeutic is to work out a dynamic balance between the existent and the ideal in the ordering of the sciences. For this reason, I will begin my discussion with a review of the functions allotted to the third branch in the Carnegie application, where Peirce not coincidentally emphasizes the disciplinary expediency of methodeutic as he frames his philosophical project within a distinctively tiered classification of the sciences.

\section{Uses of methodeutic}

Looking over the many versions of the Carnegie application, it becomes clear that Peirce is here crafting a framework that could incorporate the varying pursuits that have occupied him over the years; in a sense, he is engaging in science of review with his own thought as subject matter. It is also worth noting how Peirce, in this context, strives to find a middle ground between a defense of abstract inquiry and arguments for the broader usefulness of logic - not in a straightforwardly instrumentalist manner, for sure, but still in rather stark contrast to his strong denunciation of such considerations only a few years earlier. ${ }^{5}$ One of the outcomes is an increasingly functional justification of methodeutic along with a new construal of its limits and prospects - a demarcation that in many ways differs from Peirce's earlier characterization of speculative rhetoric cum objective $\operatorname{logic}^{6}$ as an investigation of "the laws of the evolution of thought"

5 See, in particular, the first lecture of Peirce's 1898 talks on "Reasoning and the Logic of Things.”

6 In a number of texts from the 1890s, Peirce uses the name "objective logic" as a nearsynonym of speculative rhetoric, and flirts with a quasi-Hegelian conception of the third branch of logic. As his focus turns toward method, objective logic begins to fade from the picture; it is first portrayed as a component of rhetoric/methodeutic, but seems to practically vanish after the Carnegie application. For a discussion of the relationship between rhetoric and objective logic, see Bergman (2015). 
coinciding "with the study of the necessary conditions of the transmission of meaning by signs from mind to mind, and from one state of mind to another" (CP 1.444 [c. 1896]).

Thus, Peirce contrasts methodeutic to critic (logic in the narrow sense) by noting that the former "considers, not what is admissible, but what is advantageous." Aware of the pragmatic overtones of the description, he immediately adds that it is nonetheless a purely theoretical study and as such a scientific discipline in its own right (NEM 4: 26 [1902]). From a semiotic point of view, the third branch is still - as in several characterizations given in terms of speculative rhetoric - differentiated by its focus on the sign-interpretant relation. But corroborating the end-oriented emphasis of the Minute Logic, Peirce now adds that "methodeutic looks to the purposed ultimate interpretant and inquires what conditions a sign must conform to, in order to be pertinent to the purpose" (NEM 4: 62). In view of the context, there is little doubt that this particular type of interpretant entails scientific knowledge or truth; in a variant formulation, methodeutic is defined as the study of "those laws to which a sign must conform in order to determine the interpretant to which it is intended to appeal, that is, to advance knowledge" (MS L75d: 237 [1902]). It is of course conceivable that there could be other ultimate interpretants, related to different aims; but they fall outside of the purview of the methodical delimitation of the third branch (cf. Gava 2014: 52). The methodeutic interest is focused on the knowledge-producing value of sign-interpretant relations (see MS 793: 20 [c. 1906]).

Accordingly, while Peirce emphasizes the disciplinary autonomy of methodeutic as a unique semiotic study, its scientific identity is increasingly tied to its capacity to aid other disciplines in their pursuit of knowledge. Although he stresses that methodeutic is not an art or a practical science, it is nonetheless expected to be readily useful for all other sciences, even mathematics (NEM 4: 26 [1902]). In the Carnegie application, further specifications of the third branch follow from considerations of its disciplinary functions.

[Methodeutic] has to develop the principles which are to guide us in the invention of proofs, those which are to govern the general course of an investigation, and those which determine what problems shall engage our energies. It is, therefore, throughout of an economic character. Two other problems of methodeutic which the old logics usually made almost its only business are, first, the principles of definition, and of rendering ideas clear; and second, the principles of classification. (NEM 4: 62 [1902])

In addition to the general conception of methodeutic as a study of principles guiding inquiry, this sketch involves a reference to invention that indicates a special interest in abduction. In one draft of the application, Peirce at first contends that "methodeutic is nothing but heuretic and concerns abduction 
alone," but then concedes that in its focus on discovery, this field of investigation indirectly needs to consider some other matters (MS L75d: 329-330 [1902]). ${ }^{7}$ At the same time, Peirce strongly emphasizes economic factors. Accordingly, the economy of research - a branch of economy that "considers the relations between the utility and the cost of diminishing the probable error of our knowledge" (W 4: 72 [1879]) or the relative value of scientific knowledge (CP 1.122 [c. 1896]) - is now firmly placed within the methodeutic fold. In the draft just mentioned, Peirce argues that discovery means nothing but the expediting of an event that would occur sooner or later, no matter what. ${ }^{8}$ So, he declares that "the art of discovery is purely a question of economics" and adds that "the conduct of abduction, which is chiefly a question of heuretic and is the first question of heuretic, is to be governed by economical considerations" (MS L75d: 329-330). In the final version of the application, this viewpoint has been somewhat toned down; but the economy of research clearly occupies a key position in the new disciplinary vision.

Thus, logic's culminating branch is being furnished with clearer contours and more tangible tasks as heuretic methodeutic; and at the heart of this narrower but more cogent conception lies a definite economic focus. The principal, if not sole, objective of methodeutic is to advance discovery by accelerating scientific investigation. In this setting, the function of the economy of research is primarily understood negatively; it is to aid inquiry by reducing waste of time and resources. Therefore, economy is also a key factor in abduction understood

7 From another draft:

Methodeutic has no direct bearing upon any terms or propositions or upon any kind of reasoning except that which starts hypotheses. After critical logic has pronounced a hypothesis to be justifiable (being a verifiable hypothesis which explains the surprising fact), it remains to submit the hypothesis to methodeutic in order to determine whether it should be the first among the justifiable hypotheses to be considered. No such supplementary inquiry is called for in the case of a deductive or an inductive conclusion. Indirectly, however, methodeutic treats of all kinds of signs. (MS L75e: 164-165)

8 Similar remarks can be found elsewhere, for example in "The Nature of Logical Inquiry," where Peirce contends that "we assume in methodeutic that the truth will come to light at last in any case" (MS 606: 19 [c. 1905-06]). This harks back to the famed "final opinion" of Peirce's pragmatism. In the Carnegie application, he sometimes writes in terms that suggest that this state will be reached; but what he must have in mind is the kind of "logical fatalism" that holds that "the only kind of predestination of the attainment of truth by science is an eventual predestination, - a predestination aliquando denique. Sooner or later it will attain the truth, nothing more" (CP 7.78 [c. 1905-1906]). His more considered mature position typically emphasizes the conditional and hopeful nature of the ideal truth-state (see, e.g., CP 3.432 [1896]; CP 8.118 [c. 1902]; CP 2.113 [1902]). 
broadly as a phase of research; it is concerned with the kinds of hypothesis it might pay off to entertain.

In view of this accent on the disciplinary tasks of the third branch, it may not be too much of a stretch to say that the third branch is turning into something like a refined organon - a name that Peirce hesitates to use for logic as a whole because of the unsystematic character of extant organon conceptions and its instrumental associations, but without dismissing the broader rationale behind the idea (MS 606: 10-11 [c. 1905-1906]; Kent 1987: 56). Indeed, in one manuscript (MS 1338), Peirce suggests that the key function of logic is to "weave out of the results of the phanerochemist [i.e., the phanerscopist] an organon for the empirotheorist [i.e., the metaphysician]" (LI 300 [1905]; clarifications in brackets added).

Is this emerging Peircean organon then purely heuretic - that is, restricted to the sciences of discovery - as the characterizations of the third branch of logic cited above seem to suggest? Arguably not, because in several texts - including parts of the Carnegie application - the use of methodeutic clearly reaches beyond the heuretic disciplines to practical science and science of review. Thus, in "On the Classification the Sciences," Peirce asserts that methodeutic "studies the proper way of conducting different kinds of inquiry in order to attain either the most absolute truth attainable by generations and generations of investigators, or the best attainable approach to truth that can be had in time for a practical application of it” (MS 602: 6 [c. 1902-1907]). Here, at least, the third branch is portrayed as contributing more or less directly to the development of the practical disciplines. While Peirce would deny that any philosophical discipline is a mere toolbox, methodeutic, by the very nature of its subject matter, must be at least partly instrumental at heart. ${ }^{9}$

Similarly, I would argue that the usefulness of two other prominent Peircean interests assigned to methodeutic in the Carnegie application - the augmentation of analytic definition with pragmatic clarification and the development of improved means of classification - is not strictly limited to the heuretic disciplines. The latter, in particular, serves not only classificatory sciences of discovery, but also the science of review. In fact, Peirce's proposed methodeutic memoir "On Classification" (a part of the Carnegie application) is explicitly intended to draw up "different classes of objects of human creation; such as, contrivances for keeping the skin warm, languages, words, alphabets, sciences,

9 It is of course possible to maintain that the methodeutician only studies the theory of scientific expediency, without any concern for whether his or her results are actually put to use or not. Even so, given its primary task, methodeutic cannot avoid basic considerations of the nature and needs of other kinds of inquiry. 
etc.” (NEM 4: 30 [1902] cf. NEM 4: 64-68 [1902]). Even if the outcome is meant to be "a general series of Categories of Classification," there is no systemic reason why methodeutic could not be put to use in non-heuretic inquiries. Thus, it is not surprising that Peirce expands the scope of the third branch beyond investigation of truth to consideration of methods of application and exposition (EP 2: 260 [1903]). If anything, the hierarchical positioning of methodeutic - below critic and above metaphysics - would seem to place limits on the heuretic service of the third branch.

This picture is complicated by the fact that Peirce's classifications of the sciences do not always crop up in disciplinary positions identifiable as methodeutic or science of review. In fact, remarkably often such arrangements precede the actual presentations of the individual lines of inquiry - heuretic as well as non-heuretic - in ways that suggest a distinctive ordering of the conduct of science. For the Peircean scheme, it is for example crucial that mathematics stands above logic, and that logic is rationally independent from psychology but not vice versa. These are not mere descriptions after the fact, but prescriptions built into the very system. This could of course be interpreted as a task for methodeutic, understood as a part of normative logic; but it is not clear how discoveries made in the third branch could guide inquiries higher up on the ladder of the sciences - or if they are even meant to do so. Why, for example, should an ethicist observe a methodeutic injunction against adopting principles from the more concrete sciences, if that prohibition itself is a principle disclosed by a lower discipline?

What renders all of this a particularly pertinent concern is the fact that Peirce opens his Carnegie application with a prospective memoir "On the Classification of the Theoretic Sciences of Research," producing an elaborate arrangement that is evidently intended to inform and structure all the inquiries that follow (including mathematics, categorics [phaneroscopy], and normative science); but he does not clearly state that this is a matter of methodeutic or science of review. The memoir in question is described as introductory, lacking the "convincing character" of the others. At the same time, Peirce denies that his arrangement of scientific inquiry would be prescriptive; it is supposed to be a "natural classification, not of all possible sciences, but of sciences as they exist today" (NEM 4: 15 [1902]). To some extent, at least, the classification of sciences should be based on inspections of actual scientific pursuits; but it is not clear that methodeutic is equipped to handle such tasks. Rather, to the extent that the third branch is normative, it cannot provide such a quasi-naturalistic grounding of the system. In this regard, the undertaking seems to be associated with the science of review.

Yet, the logic behind the natural classification seems to be of a philosophical character. The avowed aim of Peirce's classification is to produce a 
methodical account that will "exhibit the most important of the logical relations” among sciences (NEM 4: 15 [1902]). This involves basic principles that transcend the science of review in theoretical abstraction and scientific implications. There is certainly a temptation to interpret such canons as part of methodeutic, yet Peirce appears to evade that conclusion - possibly because it might violate some of the tenets of classification themselves.

So, the problem that is materializing here concerns the source and status of the classificatory tenets. Where should we look for these elementary principles of organization, if they are uncovered neither in methodeutic nor in science of review?

\section{Prelogical designs}

As in the Carnegie application, Peirce typically introduces his mature classifications of the sciences by postulating a two-part aim for his project - to chart "sciences in their present condition, as so many businesses of living men" and to lay out "the principal affinities of the objects classified" (EP 2: 258 [1903]) - after which he expeditiously moves on to present a ladder scheme, which proceeds from more abstract to more concrete inquiries. In the background, one can often discern a long-standing Peircean interest, the question of how to delimit and justify logical inquiry; since "logic teaches us to attain truth, the need for a systematic doctrine of logic will best appear by considering its relation to the different sciences, which are the different departments of the endeavor to attain the truth" (EP 2: 115 [1902]; cf. CP 2.119 [1902]).

Only rarely does Peirce stop to consider the basis of the rudimentary guiding principles of classification, but in the Minute Logic they are discussed within the frame of "prelogical notions." That, we must assume, excludes normative logic and the postlogical sciences, but still leaves us with some other possible candidates for a disciplinary home for the doctrines of ordering. Esthetics and ethics do not really merit serious consideration in this context, but a strong case might be made for phaneroscopy (phenomenology), the font of the philosophical doctrine of categories. In spite of some notable exceptions - including the dyadic split of the special sciences into parallel physical and psychical wings - triadism certainly tends to hold sway in Peirce's classificatory pursuits. Not implausibly, some commentators (e.g., Kent 1987; Gava 2014) have discerned a comprehensive categorial rationale underlying the perennial version of his scheme. 
Yet, there are a couple of arguments against installing the developed theory of categories at the head of the arrangement of the sciences. If the leading principles are categorial or phaneroscopic, then we are still faced with the question of their applicability in mathematics. ${ }^{10}$ And although it is true that most of Peirce's groupings turn out to be trichotomic (EP 2: 258 [1903]), ${ }^{11}$ he also expresses some serious reservations about allowing the categories to govern the scheme from the outset. In fact, he tends to avoid all direct appeals to phaneroscopic doctrine in the first stages of the undertaking, and even claims to have "carefully eschewed giving the slightest voice" to his philosophy in drawing up his classification (MS 1339: 4 [c. 1902]).

No doubt, many readers will find the above statement singularly unconvincing; even if one disregards the evident triadic patterns in Peirce's schemes, it is difficult to see how any classificatory pursuit could get off the ground without at least some philosophical guidelines to give it direction. In one draft chapter of the Minute Logic, Peirce argues that arrangement by "abstract forms of facts essentially connected with objects ... ultimately comes, in every case, to classification according to numbers; and classification according to numbers ultimately comes ... to classification according to the cenopythagorean categories one, two, three," which he then designates as "the sole and supreme" mode of classification (MS 426: 7 [1902]). In a later manuscript (MS 1338 [1905]), he states that a leading hierarchical principle - the Comtean ordering, here enigmatically designated by the proper name "Batéris" - "is fertile in trichotomies, never mind why" (LI 292); and in the discussion that follows, the explication of these basic conceptions or elements is a task assigned to "phanerochemy" (phaneroscopy). Still, in the context of the classification of the sciences, the utility of the categories is circumscribed by their very universality. As these conceptions are presumably ubiquitous, they "must be expected to show themselves not only in true natural classifications, but also in mistaken attempts at natural classification" - which, as Peirce recognizes "leaves us quite in the dark as to [the] helpfulness of a further knowledge of the categories” (MS 1343: 16-17 [1902]).

10 In the Carnegie application, Peirce expresses some concern regarding the order in which mathematics and the categories ought to be introduced, as the logical application of the latter to the former seems to derange his classification (NEM 4: 20 [1902]). With an appeal to methodeutic considerations, he concludes that it is best to let the categories emerge naturally in mathematics, before moving on to an explicit consideration of them in "categorics" (i.e., phenomenology or phaneroscopy). In a notebook entry from the same year, the study of the categories precedes mathematics (MS 339: 222r).

11 The typical trichotomy can be generally described as nomological-classificatory-descriptive; but "not all divisions are of this character" (EP 2: 258 [1903]). The practical sciences, in particular, do not follow a trichotomic model. 
What is more, the very being of the categories is uncertain in the initial states of the inquiry, and so Peirce concludes that it "will be the part of good sense to leave such matters entirely out of account until the frame-work of our classification is nearly or quite complete, and to avoid the 'high priori' method" (MS 1343: 17 [1902]).

Kent (1987: 49) conjectures that Peirce's appeal to a study of the laws of classification that precedes logic may imply mathematical inquiry of some kind. However, this interpretation leans heavily on Peirce's mature view of mathematics as the only science in no need of support from other disciplines; in the early manuscripts to which Kent refers, Peirce does not appeal to mathematical considerations, but to a theory of definition by genus and species complemented with a (proto-phaneroscopic) account of prescissive separation (W 1: 330 [1865]). It is also worth observing that Peirce, at this embryonic stage, argues that classification - like all "pure science" - considers "not what is but what is possible” (W 1: 330 [1865]). While this may be evocative of his later conception of mathematics as a hypothetical science, it does not accord with his avowed intention to classify existing rather than possible sciences (see, e.g., EP 2: 258 [1903]). Furthermore, when he later argues that a hierarchical series is a "result of any eventful evolution of class-characters," he distinguishes such natural arrangements from schemes of a mathematical origin, where cross-classifications are quite common and acceptable (EP 2: 395 [1906]). This does not mean that the latter could not be natural - notably, Peirce asserts that logical classes are of this character (EP 2: 125 [1902]) - but the primary naturalness of the scientific ordering is of the former kind.

Kent (1987: 49) also suggests that the "prelogical notions" of classification belong to logica utens, our "logic in possession" (EP 2: 892 [1901]). This is a more plausible hypothesis. In the Dictionary of Philosophy and Psychology, Peirce defines logica utens as "a classification of arguments, antecedent to any systematic study of the subject" (CP 2.204 [1902]). In the Minute Logic, he further argues that attempts to order sciences hierarchically should be preceded by general deliberations on classification and science (MS 426: 2-3 [1902]); and adds that "classification is one of the topics of logic to be dealt with more scientifically in its proper place” (EP 2: 116 [1902]). In effect, this leaves space for methodeutic elaboration; but before developing any systematic theory, we will need to make numerous classifications relying on "detached truths that can be tolerably well established at the outset” (MS 426: 3 [1902]).

But what does this "tolerable" initial determination of classificatory tenets entail? Are they simply given, in some sense self-evident for any potential inquirer? Peirce's struggles to expound this preliminary stage - mostly in the Minute Logic - should perhaps give us some pause here, as he offers several 
divergent accounts of how it is meant to shape the practice of classification. Rather than just appealing to "detached truths" of logica utens, Peirce employs and develops substantial philosophical theories along the way, in particular of final causation and purposive classification.

While Peirce acknowledges that different uses call for different modes of classifying things, he submits that the scientifically valuable arrangement should be "natural." This is a rather loaded term, and therefore he quickly explains that it does not necessarily denote "real" in a metaphysical sense. Evading the question of metaphysical reals in this context, Peirce argues that "the business of classification has no concern with them, but only with true and natural classes, in another and a purely experiential sense" (EP 2: 116-117 [1902]). But how should this reference to "experience" be understood, especially in the prelogical stages of the endeavor?

Peirce makes a distinction between classification in general, which "has reference to a tendency toward an end," and natural classification, a special case in which the final cause "is the tendency which has determined the class characters of the objects" (NEM 4: 65 [1902]). ${ }^{12}$ He further explains that by "tendency toward an end" he means "that a certain result will be brought about, or approached, and in such a way that if, within limits, its being brought about by one line of mechanical causation be prevented, it will be brought about, or approached, by an independent line of mechanical causation" (NEM 4: 65 [1902]). A natural or real class is thus a special case, which can be comprehended as "a class of which all the members owe their existence as members of the class to a common final cause" (EP 2: 117 [1902]). Peirce rejects the demand that a natural class should be determined by a singular definition, arguing that such vague, general, and longitudinal objects "cluster about certain middling qualities," from which it follows that "it may be quite impossible to draw a sharp line of demarcation between two classes, although they are real and natural classes in strictest truth" (EP 2: 118-119 [1902]). But how then does such an indeterminate class manifest itself in experience? In actual classifications, at least, we would seem to need some more concrete criteria by which to distinguish a natural from a non-natural purposive class.

Peirce's characterization of a natural classification as a "birth-al" scheme implies one possible answer: a focus on the genesis of the objects probed (MS 1343: 12 [1902]). Accordingly, he maintains that a natural scheme "has reference to the natus, or developmental origin, of its subject” (MS 1344: 10 [1902]). However, in some cases of natural classification, this underlying cause may be

12 For more on Peirce's conception of natural classification, see, e.g., Hulswit (1997) and Pape (1993). 
inscrutable; all that we can say is that there is some occult power that determines objects - e.g., chemical elements - to enter into certain detectable formal patterns or clusters. In contrast, if "it is possible to know the purposes and other governing ideas to which the things classified owe their origins," the arrangement can be labelled an intelligent natural classification (MS 1344: 10-11 [1902]; emphasis added). Objects of human creation, such as the sciences, are items that can be classified in the latter manner (cf. NEM 4: 30 [1902]).

One conceivable way to unpack this genealogical premise would be to refer to the concrete origins of scientific investigations. In parts of the Minute Logic, Peirce proposes to anchor the classificatory project in primary human instincts on the grounds that a science is a deliberate course of inquiry animated by a purpose; and "every purpose has its root in a desire, and every desire is a phase of an instinct” (MS 1343: 18 [1902]). From this evolutionary perspective, science has arisen from basic drives for self-preservation and reproduction (see, e.g., MS 1337 [1892]; CP 1.118 [c. 1896]; CP 6.500 [c. 1906]) ${ }^{13}$; and a classification of inquiries is hence derivable from broad natural objectives pertaining to feeding and procreation - aims that are then gradually subdivided and refined, eventually generating more rarefied modes of science. Such a scheme rests on the assumption that these instinctive purposes are sufficiently familiar to all human beings, thereby providing a satisfactory foundation for the arrangement.

In spite of its naturalistic appeal, there are several problems with such an instinct-based approach to the classification of the sciences. For one, it would require a rather extensive reconstruction of the evolution of inquiry from instincts ${ }^{14}$; and it is far from clear how such a story could circumvent idealized notions of origins and results. A straightforwardly genetic perspective would also have some rather unwelcome consequences for the arrangement of the sciences, as it suggests that embryonic - and eminently pragmatic - modes of inquiry would be more general in scope than later specializations, which does not accord with Peirce's conception of the relationship between the heuretic disciplines and the useful arts. Admittedly, he tends to follow such a line of

13 "In the first place all that science has done is to study those relations between objects which were brought into prominence and conceiving which we had been endowed with some original knowledge in two instincts - the instinct of feeding, which brought with it elementary knowledge of mechanical forces, space, etc., and the instinct of breeding, which brought with it elementary knowledge of psychical motives, of time, etc. All the other relations of things concerning which we must suppose there is vast store of truth are for us merely the object of such false sciences as judicial astrology, palmistry, the doctrine of signatures, the doctrine of correspondences, magic, and the like.” (CP 1.118 [c. 1896])

14 Moreover, Peirce sometimes assigns the ordering of instincts to classificatory psychical science, with no evident worries about circularity (see, e.g., CP 7.378 [1902]). 
thought primarily in connection with his reflections on the practical sciences (e. g., MS 1300 [1902]); but he also suggests that its principles can serve as a guideline for a comprehensive classification of the sciences (MS 1343: 19 [1902]). Furthermore, if a natural arrangement truly calls for a reference to the past natus of the scientific pursuit at hand, then it follows that not only physical and psychical inquiry, but even philosophy and mathematics, should be traced back to their "primitive" origins and arranged accordingly. This is obviously not the rationale of ordering that Peirce standardly follows.

This seems to suggest some unresolved tensions between teleological and genealogical perspectives. However, in the first version of the Minute Logic chapter on prelogical notions, Peirce argues that when different considerations motivating classification are properly comprehended, schemes based on purposes or governing ideas will accord with genealogical-historical arrangements.

There is no room for doubt that in case we know what ideas have brought objects into existence, they ought to be classified upon the basis of those ideas; and this is the case with the sciences. A perfectly parallel remark is equally indisputable in regard to the evolutionary classification. In case we know what the genesis of objects has really been, they ought to be classified genetically. If this be true of each of these modes of classification, they ought to coincide; and if each is truly understood, they will coincide. (MS 426: 4-5 [1902])

But do genetic and ideational considerations really fall in place as suggested? In the first version of "Prelogical Notions," Peirce avers that the erecting of the classification ought to follow a historical sequence, beginning with "those sciences which first takes birth, indeed, before science takes birth" - that is, "the arts, or practical sciences" (MS 426: 13 [1902]). The result is an interesting, but quickly abandoned, effort to unearth the dependency relations between inquiries by tracing out how more concrete arts - beginning with engineering over time require more abstract information and knowledge, thereby eventually revealing a need for more theoretical sciences. ${ }^{15}$

In the second version of the same chapter, Peirce revises this emphasis on lineage. While still granting that the tracing of more abstract inquiries to the factual needs of more concrete ones can be valuable, he now adds that "in the truer order of development, the generation proceeds quite in the other direction" (EP 2: 127 [1902]). Thus, by "genesis" he does not primarily mean "the efficient action which produces the whole by producing the parts, but the final action

15 Peirce tries to argue for a layer-by-layer erection of the structure; accordingly, the first disciplines needed by the practical sciences are identified as descriptive departments (in this case, geography and sociology). 
which produces the parts because they are needed to make the whole" (EP 2: 127 [1902]). Rather than tracing sciences to historical origins in instincts or arts, natural genealogy is then construed as a "production from ideas." From this point of view, a "science is defined by its problem; and its problem is clearly formulated on the basis of abstracter science” (EP 2: 127 [1902]). Thus, ideational genesis justifies hierarchical dependence. With a nod to the developmental point of view, Peirce argues that we "must not forget ... that a natural classification is genetic, and that a classification the result of growth will naturally be hierarchical, or genealogical” (MS 427: 144). But this "account of the existential, or natural, birth concerning relations of things" (CP 1.244 [1902]) is based on evolution by ideas or final causes and not by dynamic influences or efficient causes.

\section{The natural life of inquiry}

One upshot of the above reflections on classification - whether they are truly "prelogical" or not - is a bracketing of the categories in favor of a genealogical account, in which the governing idea or purpose of science is understood in terms of its essential problem. However, this is still somewhat nebulous. After concrete origins in instincts and disciplinary history have been discarded, experiential identification is only marginally abetted by the proposed equivalence between the governing causes and the principal problems of sciences. Given that the world of inquiry is full of pursued and potential problems, it remains to be determined which of these constitute the "one idea" from which the members of a natural class supposedly "derive their peculiar faculty" (EP 2: 125 [1902]). And how can the classifier avoid projecting personal visions and prejudices into the presumed "final causes" of the sciences?

Peirce offers a strikingly pragmatic solution. Instead of postulating final causes in a high priori mode, he proceeds to circumscribe the governing ideas by their "offspring and vehicles" (cf. EP 2: 125 [1902]). Accordingly, he characterizes the objects of classification as actual social sets of scientists and argues that the identification of disciplinary boundaries must be based on inspections of the concrete activities of such groups. However unexpected this down-toearth appeal may feel in light of the idealistic overtones of the genealogical approach, it is actually closely connected to Peirce's general notion of science as an actual form of life - or "a pursuit of living men" - which he contrasts with definitions given in terms of comprehension (scientia) and organised knowledge (EP 2: 129 [1902]). Recognising that a perfectly precise definition of "science" is 
not possible, he uses the term in a broader and a narrower sense; in the former, it refers to the collective and cooperative activity of all scientists, while the latter acceptation is that of $a$ science as it is pursued by any specific group of scientists (MS 615: 14 [1908]). Whereas communal effort is the "veritable essence of science" in both senses, a particular science is emphatically described as "a real object, being the very concrete life of a social group constituted by real facts of interrelation, - as real an object as a human carcase, which is made one by the interrelations of its millions of cells” (MS 601: 5-6 [c. 1902-1907]).

Thus, Peirce's avowed aim is to "produce a scheme which shall exhibit, as far as possible, the most real affinities of the different branches of science as these sciences exist in the minds of those who are now actively pursuing them, or better, as those men are coming to regard these affinities" (MS 1339: 5 [c. 1902]). His classification is really intended to capture "sciences as they exist today" (NEM 4: 15 [1902]); it should be neither a vision of "systematized knowledge such as the classifier hopes may some time exist” (EP 2: 129; cf. MS 1339: 2) nor a prescriptive postulation of "what sciences are the only ones possible" (MS 655: 15 [1910]). This existential criterion comes into play when Peirce argues that Comte commits the cardinal sin of positivistic nominalism in treating sciences as abstractions (MS 601: 33 [c. 1902-1907]). Put differently, there can be no real ordering of things that are not themselves real and experientially concrete; "it is only natural experiential objects that lend themselves to such a natural classification," not constructs like "plane curves or any other mere possibilities" (MS 1334: 9 [1905]).

This implies a principle of individuation primarily grounded in existing social affinities. The demarcation and description of particular sciences ought to commence from observations of what scientists actually do, or "the actual living occupation of an actual group of living men” (MS 1334: 11 [1905]).

... what I mean by a "species of science," is the actual living business to which are devoting a great part of their lives a group of men and women who enjoy certain special facilities (natural capacity, training, information, advantageous situation or opportunity, equipment etc.) which they are applying with zeal and by an enlightened method to the advancement of knowledge, the problems of the different persons of the group being so nearly the same that the students thoroughly understand one another, and any one of them could with a few months' preparation, and with the same opportunities, take up and carry on the work of another with a respectable degree of success. (MS 1339: 2-3 [c. 1902])

It should be noted how concrete this social conception of a particular science is intended to be. Firstly, Peirce underlines the need for tangible interaction; that "which holds a given aggregate of heuretic activity together and makes it one science distinct from other sciences is the social relations of those who prosecute 
it” (MS 605: 9). The solitary studies an individual do not constitute scientific inquiry. It "is only when a group of men, more or less in intercommunication, are aiding and stimulating one another by the understanding of a particular group of studies as outsiders cannot understand them" that their life is truly a science in Peirce's sense (MS 1334: 12-3 [1905]). Publication and critical examination by peers are essential rather than merely ancillary features of scientific knowledge (MS 615: 9-10 [1908]).

Secondly, in determining where to draw reasonable limits of particular sciences, Peirce maintains that he is guided by "how scientists associate themselves into societies, and what contributions are commonly admitted into one journal” (NEM 4: 15 [1902]). This gives a vital first acquaintance with the families of science - "natural classes of sciences all sorted out for us in nature itself, so long as we limit our classification to actually recognized sciences" (EP 2: 131 [1902]). The more detailed taxonomic grouping of inquiries will require closer examination of scientific practice ${ }^{16}$; but Peirce seems to hold that even the most general classification of the sciences should be grounded in a review of things like scientific associations and periodicals.

Consequently, Peirce reasons that a description of the "states of mind" of scientists - or of the social affiliations where they "feel at home" - will give us a natural configuration of the sciences, which is not a smooth slope but one "broken into unequal steps with landings, flights, and so on" (MS 615: 17 [1908]). However, this is far from self-evident, and may once again summon the specter of the high priori. One basic problem is the question of how the classifier can determine which periodicals and associations are relevant for the natural arrangement. As Peirce admits, such a scheme cannot be plausibly executed in minute detail, because it would require the recognition of any group with a journal and society as a science (MS 655: 17 [1910]). ${ }^{17}$ While he emphasizes that the borders in an intelligent natural classification may overlap in various ways (see, e.g., MS 1343: 13 [1902]), certain social groupings are apparently not to be taken into consideration at all. The deciding factor seems to be what we might dub the lifetime criterion, according to which a specific science is an activity that could conceivably occupy one individual for his or her entire life - or "a group of connected inquiries of sufficient scope and

16 In the Minute Logic and the Carnegie application, Peirce employs a taxonomic terminology derived from Louis Agassiz, with terms such as "branch," "class" and "family" indicating different degrees of generality or hierarchical position. However, his usage is not consistent, and this attempt at specification appears to have been more or less abandoned in his later classifications.

17 Peirce mentions the problematic example of the interdisciplinary group of spectroscopists. 
affinity fitly to occupy a number of independent inquirers for life" (CP 7.55 [1902]).

One can of course question whether such a potential is fully observable; but it does at least give us some relatively concrete standards by which to delimit a specific science. There is certainly a basic pragmatic appeal in the idea that sciences should be identified and individuated by inspection of existing social constellations and what scientists actually do.

Still, it is not clear that Peirce fully practices what he preaches. In particular, his divisions of philosophy seem to be more driven by the requirements of his own systematic thought than by considerations of existing social realities. While the interpretation of a natural class in terms of a concrete social group provides a solider grounding for the classification, Peirce arguably overstates his case on the occasions that he suggests that his scheme is essentially descriptive and free from idealization. As we shall see, the classificatory project involves stronger normative suppositions than its quasi-naturalistic premises seem to allow.

\section{The rational arrangement of science}

The aim of Peirce's classification is not just to individuate particular sciences, but to establish a broadly architectonic map of the significant relations between real kinds of inquiry once these have been identified. Obviously, actual disciplines support each other in many different ways (NEM 4: 227 [c. 1905-1906]); the challenge is to ascertain what links are truly germane. Here, philosophical convictions inevitably come into play. For Peirce, distinctions of form always takes precedence over differences of matter in natural classification. ${ }^{18}$ The paintings of Rafael, for example, are naturally ordered according to the character of composition or the developmental phases of the artist, but not by the predominant tinges of the pictures (MS 293: 26-27 [c. 1906]). Peirce's justification for this preference is that the classification is meant to render the objects intelligible, and form is something that the mind purportedly can assimilate and comprehend. So, while he recognizes the possibility of arranging sciences in accordance with the material relationships of inclusion, intersection, and exclusion between social groups, he considers such associations to be comparatively unimportant (MS 601: 7 [c. 1902-1907]). Of more weight are relations based on

18 Sometimes, Peirce frames this discussion in terms of how real-life inquirers go or have gone to each other for aid (see, e.g., MS 1334: 14 [1905]). However, for the most part, he opts for rational reconstruction rather than sociological or historical arguments. 
dynamical interactions between different sciences, that is, stimulation by direct compulsion rather than by reason or principle. This is the way "lower" inquiries typically influence more abstract disciplines, for example the way problems encountered in the practical sciences may urge research into theory or force attention to overlooked phenomena (MS 601: 7-8 [c. 1902-1907]). However, the truly significant relations are those where the implementation of a certain line of inquiry depends on a more or less successful execution of another. It provides an arrangement according to rational precedence; in Peirce's view, such relative priority is "the only basis for a natural or true classification of the sciences" (MS 601: 30-32 [c. 1902-1907]).

As we have seen, in the Minute Logic, Peirce traces the hierarchical character of natural classification to an evolutionary perspective. However, the more specific "anti-Baconian" idea that a broader science should precede a narrower one stems from Comte (LI 292 [1905]). ${ }^{19}$ This principle establishes a definite order for the classification, in which "the sciences form a sort of ladder descending into the well of truth, each one leading on to another, those which are more concrete and special drawing their principles from those which are more abstract and general" (CP 2.119 [1902]; cf. CP 3.427 [1896]; RLT 114 [1898]). From the opposite direction, it is a matter of doctrinal dependence that builds on "the idea that one science depends upon another for fundamental principles, but does not furnish such principles to that other" (EP 2: 258 [1903]). Peirce is well aware that principle-dependence can only provide a partial picture of disciplinary relationships (MS 1334: 15-16 [1905]); but clearly, he is convinced that a recognition of the relative taxonomic ranks of different distinctions is the key to a rational classification (MS 673: 44 [c. 1911]).

Thus, the Comtean basis on which Peirce proposes to systematically erect his classification of the sciences involves the connected tenets of generality and dependency. It is meant to afford a snapshot of interrelatedness of disciplines; and since Peirce insists that the arrangement needs to be wholly rational, actual historical development - which is such only "in a small measure" - is relegated to a secondary role in the scheme, if it is considered at all (MS 339: 169r [1899]). In this regard, he opts for the dogmatic rather than the historical perspective of Comte (cf. Comte 1896: 46). It is a synchronic rather than a diachronic standpoint.

Moreover, Peirce's classification is explicitly asymmetrical. From the point of view of generality, the more abstract sciences consider a wider range of facts,

19 In some of his writings, Peirce notes with some worry certain allegations that Comte was not the real author of the classificatory model (aired mainly by the Scottish theologian Robert Flint). In the end, Peirce dismisses these accusations of plagiarism as "petty" (EP 2: 458 [c. 1911]). 
but look less into details (NEM 4: 227 [c. 1905-1906]). Accordingly, as we move down the Comtean ladder, disciplines are supposed to become gradually narrower in scope. ${ }^{20}$ Put differently, the sciences are to be so ordered that the conclusions of a more abstract science extend without reasonable doubt to all the objects of a more concrete but dependent discipline (MS 693: 60 [1904]). Thus, from the perspective of reliance, the higher sciences establish principles or rules, which the subordinate ones can then accept as facts or foundations in their own more specific inquiries; but the lower disciplines possess no equivalent authority in the opposite direction. On the contrary, one of the motivations behind Peirce's scheme is to vindicate the relative autonomy of the more abstract sciences.

In a slightly more pragmatic vein, Peirce argues that "the results of one science, A, will often be applied by another science, B, as principles or tools wherewith to solve its problems (not, of course, without research of its own), while science, B, will perhaps suggest problems to science, A, but will not furnish it with any great aid in solving its problems" (MS 1339: 4 [c. 1902]; cf. MS 1344: 5). Sometimes, Peirce seems to suggest that a higher science borrows fields of application from the lower (see, e.g., MS 673: 45 [c. 1911]; EP 2: 456 [c. 1911]); but in general, his view is that the realization of such uses is a task for the more concrete discipline. Yet, in a broader sense, the lower sciences are expected to provide valuable suggestions or data for the more abstract inquiries (PM 9 [1895]; CP 3.427 [1896]; RLT 114 [1898]; MS 693: 67 [1904]; NEM 4: 227 [c. 1905-1906]).

This implies that there might, after all, be a kind of mutual dependence underpinning Peirce's rational arrangement of the sciences. Gava (2014: 21-22) has explicated this in term of an architectonic precept of factual dependence that complements logical dependence (or principle-dependence, as I prefer to call it) as a relation essential to understanding Peirce's scheme. In this, Gava sees deep structural parallels to the theory of categories, which is not wholly without justification. However, as Gava also acknowledges, any relations of factual dependence in Peirce's classification of the sciences are far weaker than the principles guiding the analysis of the categories. Arguably, the word "dependence" is too strong in this case, as Peirce maintains that whatever "instances" a higher science might borrow from a lower one, they are in the end dispensable from the point of view of the more abstract discipline (MS 605: 4 [c. 1902-1907]).

Peirce explicitly rejects the view that a rational classification of the sciences could be based on reciprocal dependence. It would be a "self-supporting cycle"

20 The advantage of this narrower range of objects is the possibility to pursue more minute inquiries (MS 693: 67 [1904]). 
that would ultimately rest on nothing” (CP 8.167 [c. 1903]) - like two lying witnesses sustaining each other's credit in court (MS 1334: 33 [1905]). Peirce requires that supporting propositions be independent of each other, and argues that the "reason why it is quite impossible for two sciences reciprocally to supply one another with principles is simply that no two things can depend upon each other in the same way" (MS 693: 48 [1904]). In the Adirondack lectures, Peirce specifies the relevant dependency in terms of conditions of disciplinary existence: "no two sciences can depend each upon results of the other for principles without which it cannot exist as a science” (MS 1334: 31 [1905]). This suggests what might be called a criterion of indispensability. The lower sciences are, in certain respects, vitally dependent on the more abstract disciplines, and it is these essential relations that the hierarchical arrangement strives to depict in diagrammatic form. The opposite does not apply; this is a one-way street. $^{21}$

This repudiation of the mutual support theory brings us to one of the most controversial questions of Peirce's classification. In its weaker version, the Comtean rationale merely stipulates that certain disciplines are allowed to appropriate principles from certain others. However, in the passages cited above, we find a stronger implication of essential dependence: the suggestion that lower sciences in principle require the higher disciplines.

Gava (2014) proposes to spell out this unsymmetrical dependency in terms of the operation of prescission, which Peirce introduces in the context of his early theory of categories. There are certainly suggestive correspondences between prescissive separation and strong principle-dependence. In particular, Peirce's generic definition of prescission as "supposing a state of things in which one element is present without the other, the one being logically possible without the other" (EP 2: 270 [1903]) seems to accord with the doctrine of the relative autonomy of more abstract disciplines (mathematics is prescindable from phaneroscopy, but not vice versa). But the implied assumption that a lower science cannot even be conceived of without supposing the existence of a higher one (cf. CP 1.549 n. 1) feels less plausible. At least, few logicians appear to have recognized that the formation of their science entails the supposition of phaneroscopy. And even if relations between sciences could be described in terms of prescindability, this does not in itself capture the fundamental character of dependence that is central to the Comtean outlook.

21 However, in "Qualitative Logic" from 1886, Peirce speaks of the "hierarchical plan of classification," typical of zoology and botany, as an Aristotelian prejudice; and he suggests that chemistry-style cross-division provides one viable alternative approach (W 5: 359-360). 
In its strongest form, principle-dependence manifests itself as a natural demand for a specific sequence in the conduct of inquiry. Thus, after declaring that "rational governance" is naturally more important than dynamical relationships between the scientific disciplines, Peirce argues that there is, "in the nature of things, a determinate order of succession researches must follow, if they are to be successful" (MS 601s: 9-10 [c. 1902-1907]). Arguably, this is a different, far more consequential contention than the notion that sciences may be retrospectively arranged on grounds of generality and abstractness. For Peirce not only suggests that inquiries can be ranked based on principle-dependence; he also alleges that there is a specific order to which successful research must conform. Here, the classification of sciences is not a mere matter of rational reconstruction; it is rather a strong prescription for how inquiry ought to be organized.

This seems to clash with Peirce's rejection of taxonomies of conceivable sciences, discussed above - that is, with the idea that the classification only ought to model existing inquiries, understood as the industries of actual scientists. But as already noted, Peirce does not fully adhere to the existential criterion in his own practice. He postulates several sciences that possess an uncertain existence at best. Is it really plausible to argue that Peirce's phaneroscopy, esthetics, or ethics - or, for that matter, the semiotic sub-disciplines grammar, critic, and methodeutic - are properly identifiable and delimited in terms of concrete endeavors of his time? Although some of the names may suggest extant disciplines, it would be quite a stretch to claim that those inquiries - as practiced by an actual social group, then as now - would fall in line with the Peircean conceptions.

It is perhaps in view of such concerns that Peirce sometimes qualifies the criterion of existence by acknowledging that his classification may cover not only present sciences, but also those "whose birth seems to be promised" (MS 655: 15 [1910]). It is not quite clear how far a conscientious classifier is allowed to speculate on matters like this. On the one hand, Peirce submits that such contemplation ought to be restricted to how existing scientists are just now coming to regard the affinities between different branches of science (MS 1339: 5 [c. 1902]). We are not told how such insight is to be obtained, but it is most likely to be anchored in some kind of empirical evidence. On the other hand, Peirce asserts that "knowledge which is altogether inapplicable to the future is nugatory"; and thus, "our classification ought to have reference to the science of the future, so far as we are now able to foresee what the future of science is to be” (CP 7.56 [1902]). In a letter to William James, Peirce takes this line of argumentation one step further. 


\begin{abstract}
My classification of the Sciences is ... intended to be useful in the future, and therefore is not absolutely confined to what exists. Indeed, I found it quite impossible to state the relations between the sciences without, on the one hand, relying exclusively upon what the members of the different groups have said, - in which case the ideas governing my classification would be antiquated beyond what one would suppose before he tried that method, - or else one must speculate upon what seems to be in the atmosphere of science but has perhaps never yet been uttered. Scientific ideas do not get uttered until long after they have been influential. The consequence is that I found I could make a useful classification only by adopting as a skeleton of it my own notions of how the sciences ought to be related. (EP 2: 500 [1909])
\end{abstract}

Given this rather telling admission, Peirce's arrangement of the sciences would not only allow, but even demand prescriptive conjecture on top of the description of extant activities. The excuse for such a move is primarily methodeutic; reasonable estimations regarding the near future of science are permitted to the extent that they can facilitate discovery (CP 7.56 [1902]). In spite of the professedly cautious starting points of the classificatory project, what eventually materializes is more like a regulatory scheme - something that at least implicitly involves recommendations and directives for the conduct of inquiry - than a mere mapping of existing lines of investigation.

The suggestion here, then, is that it is in methodeutic that the full classification of the sciences -normative and descriptive - is worked out. On the one hand, this involves an explication of certain prelogical notions, or of the classificatory principles of our "methodeutica utens." On the other, the activity can be said to encompass pursuits and results that Peirce typically associates with science of review. Put differently, methodeutic is actively involved in the formation of a synthetic philosophy of science, something that Peirce does not consider to be a part of heuretic inquiry. This calls into question the strict Comtean principle of rational precedence - or at least the definite division of labor implied by the hierarchical model - as the normative part cannot be pursued successfully without consideration of the more descriptive aspects of the arrangement of the sciences.

Thus, I would argue that when Peirce suggests that it is desirable to obtain an idea of the logical interdependence of the sciences in logic itself (MS 673: 44 [c. 1911]), this very need requires a methodeutic that looks upward and downward in the ladder of the sciences - not only by being useful for lower inquiries, but also in the sense of using reviews of extant activities as a basis for the formation of normative schemes. For this is not just a matter of postulating ideal models of scientific inquiry; even if the criterion of existence is relaxed, it is nonetheless meant to be a vital factor in keeping the enterprise grounded in extant reality. In this respect, methodeutic seeks a balance between the descriptive and the normative in ordering sciences for the benefit of investigation. 
But what, then, becomes of the proposition that principle-dependency determines the proper order of inquiry? And what sway do the normative considerations of methodeutic hold over the purportedly more abstract sciences of mathematics, phaneroscopy, esthetics, ethics, grammar, and critic?

\section{A Question of principles}

Peirce seems to waver when it comes to the question of making use of the results of "lower" sciences in the culminating part of logic. On one side, we find comments that suggest that the study of methodeutic requires an extensive empirical review of actual scientific inquiry, if not hands-on experience of different types of research and their methods (CP 2.110 [1902]; NEM 3: 207 [1911]). In the third branch, Peirce even allows for a certain relaxing of his otherwise absolute ban on psychological considerations in logic (CP 2.107 [1902]; MS 633: 3 [1909]); and sometimes, he goes so far as to permit methodeutic to make use of all pertinent results of science (MS 637: 16 [1909]). Yet he also insists that it is "after the more rigorous and general principles of methodeutic have been worked out that a survey of the various methods leading science to the truth is needed" (MS 693a: 212-214 [1904]; emphasis added). This suggests a top-down approach, in which methodeutic is first worked out in abstraction, after which work on the science of review can ensue. With reference to his professed rejection of the mutual support theory, Peirce rebuffs the view that the third branch could be founded on a study of special sciences; the contention that "you are first to make your researches and after that inquire how they ought to be made" is likened to "locking the barn door after the horse is already stolen” (MS 1334: 28 [1905]).

It is not fully clear to me why Peirce so strongly argues that any preceding examination of actual researches and methods would violate the prohibition against reciprocal dependence with regards to principles. This may be an unwelcome by-product of the hierarchical outlook of his Comtean classification; it has a tendency to guide our thinking in a principled top-to-bottom direction, sometimes concealing what may be important dynamical influences between inquiries. In any case, to me it seems quite plausible to maintain that surveys of concrete investigations provide vital materials for the more abstract inquiry. And not only as data, but also as methodeutically significant stimuli that can advance the development of the third branch, which itself has been allotted the task of developing more efficient courses of research. 
A related concern stems from the purported dependencies between the three logical sciences. As expected, Peirce argues that each branch depends on the one that precedes it (EP 2: 260 [1903]). Thus, the "proper development of methodeutic must be based on an account of speculative grammar, by means of a scientifically exact intermediate doctrine of logical critic which shall show just wherein the validity of the different forms of thought consists" (LI 300 [1905]). Restricted to a moderate conception of principle-dependence, this feels relatively uncontroversial - although it might be prudent to qualify the "must" in certain respects. However, when Peirce argues that methodeutic "does not begin its work until the whole frame-work of the science [of logic ${ }^{22}$ ] has been firmly established" (MS 633: 3 [1909]), then we are on much thinner ice. Taken literally, this means that the third branch should wait for critic, which in turn should wait for grammar to get its act together (cf. EP 2: 256 [1903]). In fact, if Peirce were to follow this guideline with respect to the normative sciences, then he should put logic as a whole on hold until esthetics and ethics are ready to provide the required principles - something he obviously does not do, not even after acknowledging the order of normative inquiries.

Similar arguments could be concocted with regard to the relations of any two hierarchically ordered disciplines; in its strongest form, it would entail that lower sciences would so dependent on the higher that genuine progress in the former would be all but impossible until the latter are firmly established. Put into practice, this feels almost preposterous; yet, it is evidently in play when Peirce maintains that ethics needs to come to definite conclusions "before one can form any sound system of logic" (CP 2.120 [1902]). This is simply too strong a presupposition - one that is frankly implausible in view of actual developments in these disciplines. From a methodeutic viewpoint, it is certainly possible to argue that certain conceptions of esthetics and ethics may be needed for the expedient development of logic. But that is a normative perspective on how expected inquiries should be most advantageously conceived and arranged; and to allow such indefinite reflections about future possibilities to block inquiry in the here and now would be plainly un-Peircean.

In general, one of the main dangers of a hierarchical model such as Peirce's classification of the sciences is that it invites overly rigid interpretations of the interrelations between inquiries. This does not mean that we would have to abandon the idea of principle-dependence and the order outlined by Peirce. But especially in methodeutic, which needs to take a broad and inclusive view of

22 This passage is ambiguous; "the science" may also refer to psychology. However, it is highly unlikely that Peirce would advocate that the work of methodeutic needs to wait for the firm establishment of the framework of a special science. 
scientific activities, the delimiting aspects of the scientific hierarchy are a risk. To the extent that methodeutic is locked into position beneath grammar and critic, its primary role in his system is clear; it is to provide principles for metaphysics and the special sciences - and perhaps for science of review and practical science as well. But is not methodeutic meant to be of use for all types of inquiry, even those above it in the hierarchy, all the way up to the most general science of them all?

In the Carnegie application, we find Peirce discussing the "methodeutic interests" of mathematicians and the aid that a "good logical methodeutic" may provide for mathematics (e.g., NEM 4: 46 [1902]). At first blush, this may suggest a breach of the most basic tenets of his classification. Indeed, Peirce often emphasizes that mathematics is in no need of assistance from the theory of logic. The most abstract science gets along with an unsystematic logica utens; methodeutically, mathematics serves as its own logic (NEM 4: 37 [1902]; NEM 4: 45 [1902]; CP 7.81 [1902]). Yet, in analyzing the procedure of mathematics, Peirce repeatedly refers to theorematic and corollarial reasoning, a specifically methodeutic distinction (MS 339: 196r [1901]). A theorematic proof "differs from a corollarial proof from a methodeutic point of view, inasmuch as it requires the invention of an idea not at all forced upon us" (NEM 4: 8 [1901]). In the context of mathematics, this entails the creative construction of diagrams needed for discoveries; and the particular mathematical interest lies in the methodeutic "devices which have to be employed to bring those new relations to light" (CP 4.370 [c. 1903]). ${ }^{23}$

Consequently, it is evident that methodeutic considerations can be useful for the mathematician. ${ }^{24}$ But of course, this is not the same thing as saying that methodeutic would be essential for mathematics (cf. Gava 2014: 42). Employing a useful Peircean distinction, such a conclusion could be interpreted as an exemplar of the "not uncommon, and not specially pernicious, error of mistaking a methodeutic rule for a fundamental principle” (MS 601: 11 [c. 1906]). Unfortunately, Peirce does not fully clarify this distinction; but we may surmise that methodeutic rules are procedures that may in different ways facilitate inquiry, in particular by speeding up the process of discovery.

23 See Gava (2014: 39-42), for a more thorough discussion of mathematics and theorematic reasoning.

24 However, in one draft of the Carnegie application, Peirce explicitly restricts the application of the third branch to metaphysics and the special theoretical sciences, and concludes that "the methodeutic utility of the science of logic, although it is beyond price, is pretty narrowly limited" (MS L75a: 31-33 [1902]). 
Yet, one can still reasonably ask whether there might not be some methodeutic tenets that are truly necessary also for more abstract sciences. The question hinges on the concept of "principle." In spite of frequently employing the term, Peirce does not really elucidate his usage (Short 2007: 62). In some cases, the implications are obvious enough. For example, categorial principles are handed down from phaneroscopy, and esthetics establishes the summum bonum. But some of Peirce's expressions suggest that such doctrines may be treated as leading or regulative principles by lower disciplines, which raises a crucial question: what about the general leading principles of inquiry, such as fallibilism, synechism, and the overriding principle of hope (that truth is discoverable)? Are they not in a broad sense methodeutic, yet indispensable for all heuretic sciences?

Peirce would probably reject such a conclusion on the grounds that truths "that ordinary observation teaches every intelligent person or that have been handed down from generation to generation from prescientific ages as common sense do not belong to any science nor to science in general, though science may be in part founded on them" (MS 615: 15 [1908]). Although Peirce sometimes avers that methodeutic includes a systematic study of the presuppositions of reasoning, he identifies these methodeutic objects as specific presumptions in contrast to general presumptions, where the latter are roughly analogous to the prelogical - even prescientific - principles of the logica utens on which all inquiry purportedly rests. Still, although methodeutic does not have a monopoly on such leading principles, a case might be made that their identification and further elaboration into highly general but potentially pragmatic guiding directives of inquiry is a prime task for the methodeutician (cf. Gava 2014: 44). When Peirce envisions "a method of discovering methods," based on "a theory of the method of discovery" that "should be founded on a general doctrine of methods of attaining purposes, in general," which "in turn, should spring from a still more general doctrine of the nature of teleological action, in general" (CP 2.108 [1902]), he virtually summons a hierarchy of inquiries along Comtean lines. However, from the opposite point of view, this can be construed as an example of how the needs of methodeutic can call for and thereby partly inform - more abstract lines of investigation. Furthermore, if not to the methodeutician (or perhaps more broadly, the "semiotic" logician or philosopher), to whom is the task of elucidating leading principles of inquiry to be assigned? For the time being, at least, it may be best to construe efforts to articulate prelogical notions as jobs for the third branch. There is some mutual support going on here, but arguably not of a vicious kind; it is a justifiable interdependence because of its potential contribution to the advancement of inquiry. 
For Peirce, the special value of logical methodeutic is that it can aid "the economy of every other science” (NEM 4: 29 [1902]). This perspective is arguably linked with the broader normative implications of methodeutic.

The purpose and utility of logic ... lies in its final achievement of a methodeutic for the guidance of thought; and from this point of view logic is the theory of the self-control of thought in order to realize its intention, which is truth. So regarded, logic may be called a special kind of ethics, if by ethics we mean the theory of the self-control of conduct in order to realize a deliberately adopted purpose. (MS 602: 8 [c. 1902-1907])

Here, Peirce connects the usefulness of methodeutic as a guide for deliberation with the pre-eminently normative notion of self-control. This standpoint is connected to the general utility of methodeutic for inquiry; basically, the economy of research performs an inhibitory function in scientific investigation, analogous to that of self-control in deliberate reflexion. It is fundamentally a matter of expediting matters by avoiding waste, a methodical control of "impulses." Accordingly, Peirce argues that "the methodeutic task of logic is to find such methods as must hasten the progress of opinion toward its ultimate bourn" (MS L75c: 90 [1902]).

However, does this not also entail that ethics, understood as a science of self-control (MS 1339: 12), is dependent on methodeutic for principles, as logic provides the tools needed to achieve self-control? Peirce would no doubt reject such an argument, as it leads to the dreaded circle of reciprocal support. Again, we do not need to reject principle-dependence. But the way esthetics and ethics are introduced as higher normative sciences in Peirce's system is quite revealing; they are not discovered as extant inquiries, but rather called for by the purposive needs of logical inquiry. It is difficult to see what esthetics and ethics would do as autonomous disciplines, if not given direction by the demands of logical inquiry and its methodeutic objectives in particular. ${ }^{25}$ Such quasi-teleological considerations are, broadly speaking, a matter of dynamical inducement rather than of rational governance in terms of principle-dependence. Peirce does not sufficiently acknowledge the extent to which his system, especially with regard to the philosophical disciplines, is held together by such purposive influences on the higher sciences by the lower disciplines.

In this respect, then, the culminating branch of logic can be said to play a key dynamic role in the eventual constitution of Peirce's classification of the sciences. Methodeutic places demands on critic and grammar, and the three

25 On somewhat different grounds, Liszka (2010) has also argued that speculative rhetoric influences critic and ethics in a more substantial way than the classification of the sciences would seem to allow. 
divisions of logic (possibly including a broader conception of the third branch as methodeutic and rhetoric) actively influence the formation of such Peircean ethics and esthetics by their needs.

To sum up this argument, I hold that the elucidation of such dynamical requirements should be an important part of methodeutic work, virtually as important as the clarification of principle-dependencies. It is the former type of influences that justifies the postulation of sciences not yet fully in existence. At the same time, methodeutic has a duty to put certain checks on such speculations - not in order to block inquiry, of course, but to advance inquiry by expediting it. It is a precarious and eminently fallible enterprise, in which mistakes are inevitably made in both directions. And this, in turn, provides a justification for pursuing a methodeutic that takes a broad view of inquiry, including within its scope normative considerations, grounded descriptions of extant practices, and researches into the ideational and historical evolution of scientific disciplines.

\section{References}

Bergman, Mats. 2015. The highest branch of logic? On a neglected question of speculative rhetoric. Sign Systems Studies 43(4). 463-482.

Comte, Auguste. 1896. The positive philosophy, Harriet Martineau (trans.). London: George Bell. Gava, Gabriele. 2014. Peirce's account of purposefulness: A Kantian perspective. New York: Routledge.

Hulswit, Menno. 1997. Peirce's teleological approach to natural classes. Transactions of the Charles S. Peirce Society 33(3). 722-772.

Kent, Beverley. 1987. Charles S. Peirce: Logic and the classification of the sciences. Kingston: McGill/Queen's University Press.

Liszka, James J. 2010. Peirce's revolutionary concept of rhetoric. In Mats Bergman, Sami Paavola, Ahti-Veikko Pietarinen \& Henrik Rydenfelt (eds.), Ideas in action (Nordic studies in pragmatism 1), 118-133. Helsinki: Nordic Pragmatism Network.

Pape, Helmut. 1993. Final causality in Peirce's semiotics and his classification of the sciences. Transactions of the Charles S. Peirce Society 29(4). 581-606.

Peirce, Charles S. 1931-1966. The collected papers of Charles S. Peirce, 8 vols., C. Hartshorne, P. Weiss \& A. W. Burks (eds.). Cambridge: Harvard University Press. [Reference to Peirce's papers will be designated $\mathrm{CP}$ followed by volume and paragraph number.]

Peirce, Charles S. 1967. Manuscripts in the Houghton Library of Harvard University, as identified by Richard Robin, Annotated catalogue of the papers of Charles S. Peirce. Amherst: University of Massachusetts Press. [Reference to Peirce's manuscripts will be designated MS]

Peirce, Charles S. 1976. The new elements of mathematics, 4 vols., C. Eisele (ed.). Berlin \& New York: Mouton de Gruyter; Atlantic Highlands, NJ: Humanities Press. [Reference to Peirce's New Elements will be designated NEM followed by volume and page number.] 
Peirce, Charles S. 1982-. Writings of Charles S. Peirce, 6 vols., M. Fisch, E. Moore \& C. Kloesel (eds.). Bloomington: Indiana University Press. [Reference to Peirce's writings will be designated $W$ followed by volume and page number.]

Peirce, Charles S. 1992. Reasoning and the logic of things: The Cambridge conferences lectures of 1898, K. L. Ketner (ed.). Cambridge: Harvard University Press. [Reference to Peirce's Reasoning and the Logic of Things will be designated RLT followed by page number.]

Peirce, Charles S. 1998. Essential Peirce: Selected philosophical writings, vol. 2 (1893-1913), Peirce Edition Project (eds.). Bloomington: Indiana University Press. [Reference to vol. 2 of Essential Peirce will be designated EP 2.]

Peirce, Charles S. 2009. The logic of interdisciplinarity: The Monist-series, E. Bisanz (ed.). Berlin: Akademie Verlag. [Reference to Peirce's Logic of Interdisciplinarity will be designated LI followed by page number.]

Peirce, Charles S. 2010. Philosophy of mathematics: Selected writings, M. E. Moore (ed.). Bloomington: Indiana University Press. [Reference to Peirce's Philosophy of Mathematics will be designated PM followed by page number.]

Short, Thomas L. 2007. Peirce's theory of signs. Cambridge: Cambridge University Press. 